\title{
O PENSAMENTO DA CEPAL DE 2010 A 2018: O ENFOQUE NA MUDANÇA ESTRUTURAL PRODUTIVA PARA IGUALDADE (MEPI)
}

\author{
Isaías Albertin de Moraes ${ }^{a}$ \\ Hermano Caixeta Ibrahim \\ Leandro Pereira Morais ${ }^{c}$
}

${ }^{a}$ Estudante do Doutorado em Ciências Sociais da Universidade Estadual Paulista (UNESP) e pesquisador do Núcleo de Extensão e Pesquisa em Economia Solidária, Criativa e Cidadania (NEPESC) da UNESP. Araraquara, SP, Brasil. ORCID: https://orcid.org/0000-0003-1839-803X.

${ }^{b}$ Estudante do Doutorado em Economia do Desenvolvimento da Universidade Federal do Rio Grande do Sul (UFRGS). Porto Alegre, RS, Brasil. ORCID: https://orcid.org/0000-0003-0189-2154.

'Professor do Departamento de Economia da UNESP e coordenador do NEPESC. Araraquara, SP, Brasil. ORCID: https://orcid.org/0000-0002-3945-9455.

\section{Recebido em 10 de fevereiro de 2019}

Aceito em 03 outubro de 2019

RESUMO: O artigo tem como unidade de análise a Comissão Econômica para América Latina e Caribe das Nações Unidas (CEPAL/ONU). O objetivo é de investigar a atual fase de seu pensamento com forte enfoque na igualdade. A pesquisa categoriza $o$ pensamento cepalino em duas fases distintas: a primeira, do Estado-empreendedor e método histórico-estruturalista (1948-1990), e a segunda, do Estado-gerencial e método histórico-neoestruturalista (1990-atualidade). A hipótese elencada é de que o pensamento cepalino desde 2010 se afastou da proposta de Transformação Produtiva com Equidade (TPE) - defendido, inicialmente, pelo Neoestruturalismo - e está estabelecendo uma nova concepção: Mudança Estrutural Produtiva para Igualdade (MEPI) A pesquisa optou em priorizar como procedimentos técnicos uma abordagem

Correspondência para: Isaías Albertin de Moraes

Contato: isaias.a.moraes@unesp.br 
sistemática por meio da avaliação crítica dos dados bibliográficos e documentais sobre a temática, sobretudo os próprios documentos produzidos pela CEPAL.

PALAVRAS-CHAVE: CEPAL; desenvolvimento econômico; política econômica; história econômica da América Latina.

CLASSIFICAÇÃO JEL: N16; O11; 054. 


\title{
ECLAC'S THINKING FROM 2010 TO 2018: THE FOCUS ON STRUCTURAL CHANGE FOR EQUALITY (MEPI)
}

\begin{abstract}
The article's unit of analysis is the United Nations Economic Commission for Latin America and the Caribbean (ECLAC/UN). The purpose is to investigate the current phase of its thinking with a strong focus on equality. The research categorizes ECLAC thought in two distinct phases: first, the State-entrepreneur and historical-structuralism method (1948-1990), and second, the management-State and historical-neostructuralism method (1990-present). The hypothesis is that the ECLAC thought since 2010 has moved away from the Productive Transformation with Equity (TPE) proposition - initially defended by Neo-Structuralism - and is establishing a new conception, namely the Structural Change for Equality (MEPI). The present study chose to adopt as technical procedure a systematic approach through the critical evaluation of bibliographic and documentary data on the subject, especially the documents produced by ECLAC.
\end{abstract}

KEYWORDS: ECLAC; economic development; economic policy; economic history; Latin America. 


\section{INTRODUÇÃO}

O presente estudo tem como unidade de análise a Comissão Econômica para América Latina e Caribe da Organização das Nações Unidas (CEPAL/ONU) e empenhou-se em investigar o descolamento do pensamento da CEPAL da Transformação Produtiva com Equidade (TPE) - defendido, inicialmente, pelo Neoestruturalismo - para uma nova concepção: Mudança Estrutural Produtiva para Igualdade (MEPI). A realização de uma pesquisa que identifique a importância e as aplicações da CEPAL, com enfoque na sua nova fase (2010 a 2018), justifica-se e encontra-se relevância para melhor aproveitamento e conhecimento do impacto da instituição como um importante think tank e como uma escola de pensamento autêntica latino-americano.

A revisão dos principais estudos realizados sobre CEPAL e desenvolvimento econômico da América Latina e Caribe possibilitou a inferência de que há excelentes textos que se dedicam aos tempos primórdios da instituição, porém há parcas pesquisas que tratam dos estudos cepalinos contemporâneos. Este trabalho procura lançar luzes sobre o passado, mas, primordialmente, preencher algumas lacunas sobre as contribuições da CEPAL na contemporaneidade.

A pesquisa categoriza o pensamento cepalino em duas fases distintas: a primeira caracterizada pelo Estado-empreendedor e o método histórico-estruturalista (19481990), e a segunda, pelo Estado-gerencial e o método histórico-neoestruturalista (1990-atualidade). A hipótese elencada é a de que o pensamento cepalino, recentemente, está buscando superar a proposta de TPE - um dos preceitos centrais do Neoestruturalismo - e preconizando a MEPI. Na primeira seção do artigo se apresentam os conceitos básicos da metodologia, da teoria e da retórica cepalina. Na segunda seção, o texto concentrou-se em expor a síntese de ideias que assentiram para o avanço teórico e discurso da CEPAL rumo à MEPI.

Para verificar a hipótese tipificada pela pesquisa, optou-se em priorizar como procedimentos técnicos metodológicos uma abordagem sistemática por meio da avaliação crítica dos dados bibliográficos e documentais sobre a temática, sobretudo os próprios documentos produzidos pela CEPAL. A concepção de que a busca pela igualdade deveria se tornar o foco dos estudos da Comissão surge em 2010 com o documento: "A hora da igualdade: brechas para fechar, caminhos por abrir" (CEPAL, 2010).

Desde então, os relatórios anuais da CEPAL estão enfatizando essa perspectiva e estruturando, de forma sistemática, uma síntese de ideias que aos poucos está evoluindo o paradigma neoestruturalista na Comissão. Os principais documentos até o momento, além do já citado, são: "Mudança estrutural para igualdade: uma visão integrada do desenvolvimento" (2012); "Pactos para a igualdade: rumo a um futuro sustentável” (2014); "Horizontes 2030: a igualdade no centro do desenvolvimento susten- 
tável" (2016); e "A ineficiência da desigualdade" (2018). A revisão da literatura se concentra nesses cinco textos de períodos de sessão da CEPAL em virtude de serem os documentos mais relevantes produzidos pela Comissão no recorte historiográfico proposto pela pesquisa. $\mathrm{O}$ autor contou ainda com a experiência de realizar aperfeiçoamento no tema das economias latino-americanas na própria sede da CEPAL de junho a setembro de 2017,, possibilitando, assim, manter conversas com diretores e realizar consultas em acervos.

\section{AS FORMULAÇÕES ESTRUTURALISTAS DA CEPAL}

As atividades da CEPAL iniciam-se em 07 de junho de 1948 em Santiago do Chile. A CEPAL nasceu de uma iniciativa latino-americana de reação ao avanço do liberalismo econômico apregoado pelos Estados Unidos da América (EUA) no pós-Segunda Guerra Mundial e das queixas, por parte dos países da América Latina, de exclusão do Plano Marshall e do Plano Colombo, ocasionando falta de acesso aos investimentos externos (CEPAL, 1988).

O seu primeiro secretário executivo foi o economista mexicano Gustavo Martínez Cabanas que, em um primeiro momento, colocou a necessidade de organizar o "Estudo Económico de América Latina”. Em fevereiro de 1949, Cabañas convidou Raúl Prebisch, renomado economista argentino, criador e dirigente do Banco Central da Argentina, para colaborar na elaboração desse documento. Em maio de 1949, foi apresentado o "Estudo Económico de América Latina", o primeiro da série, e com uma retórica quase exclusivamente descritiva em reunião organizada pela CEPAL em Havana (CEPAL, 1949). Na mesma ocasião, Prebisch (1949), ainda, apresentou o seu estudo: "El desarrollo económico de América Latina y sus principales problemas" (texto que ficou conhecido como o Manifesto da CEPAL). Com ele, Prebisch faz uma reavaliação sobre a transferência de diretrizes da economia clássica para o continente latino-americano. Nasciam, com esses trabalhos, um modelo e um padrão teórico-científico que mudariam drasticamente a concepção de mundo pela comunidade dos países latino-americanos (CEPAL, 1988).

Em maio de 1949, Prebisch assumiu como secretário executivo da CEPAL. O argentino ocupou o cargo até 1963. A equipe econômica da CEPAL, nesse período,

\footnotetext{
Desde 2000, a CEPAL organiza a Escuela de Verano de la CEPAL sobre Economías-Latinoamericanas com duração de aproximadamente três meses. Para mais informações: <https://www.cepal.org/es/summer-school-2017>.
} 
contou com importantes nomes como Celso Furtado, Jorge Ahumada, Aníbal Pinto, Cristóbal Lara, José A. Mayobre, Manuel Balboa, José Medina Echavarria, Victor Urquidi, David Pollock, Louis Swenson e Osvaldo Sunkel. Por focar seu diagnóstico nas estruturas produtivas dos países periféricos, em especial os países latino-americanos, os economistas cepalinos, sobretudo Prebisch e Furtado, lançaram um modelo analítico e uma síntese de ideias até então inéditos para o exame dos problemas econômicos e sociais de países subdesenvolvidos: o modelo histórico-estruturalista (BIELSCHOWSKY, 2000).

O trabalho seminal de Raúl Prebisch (1949) dividiu a economia mundial entre um centro hegemônico industrial e uma periferia dependente agrária, denunciando a existência de um processo de desenvolvimento originalmente desigual. Prebisch (1949) explicou como as características das economias periféricas determinam um desenvolvimento estrutural pouco diversificado e pouco integrado. Nesses países, um setor primário-exportador dinâmico é incapaz de difundir o progresso técnico, aumentar a produtividade e permitir o crescimento sustentado dos salários reais. Como resultado, na periferia a estrutura produtiva é especializada e heterogênea, enquanto que nas economias centrais é diversificada e homogênea. Na visão do autor:

A política de desenvolvimento tem que se basear em uma interpretação autêntica da realidade latino-americana. Nas teorias que recebemos e continuamos a receber dos grandes centros, há com frequência uma falsa pretensão de universalidade. Tocanos essencialmente, a nós, homens da periferia para corrigir essas teorias e introduzir nelas os elementos dinâmicos que requerem para aproximar-se de nossa realidade. (PREBISCH, 1964, p. 27)

Dessa forma, Prebisch (1949) questionou, particularmente, a teoria das vantagens comparativas desenvolvida pelo economista David Ricardo, propagada pela Escola Liberal Clássica, então vigente como principal estratégia de comércio internacional. Alicerçada em dados do comércio internacional obtidos pela ONU, a CEPAL, nessa primeira fase, embasada no método histórico-estruturalista, afirmou que o livre comércio e a especialização produtiva levavam a uma deterioração dos termos de troca entre, de um lado, os países periféricos, agrícolas e atrasados, e, do outro, os do centro, industrializados e desenvolvidos. Isto é, uma piora da balança dos preços de exportação vis-à-vis os preços de importação de produtos internacionais. O diagnóstico apontado explicita que os preços dos produtos primários - usualmente exportados pelos países latino-americanos - tenderiam a cair em relação aos industrializados, fazendo com que as exportações de bens primários tivessem que ser aumentadas constantemente para suprir as necessidades de bens industriais nos países periféricos. 
O método histórico-estruturalista cepalino preocupa-se com os determinantes históricos e sociais que condicionam a distribuição de renda, o avanço da produtividade e das condições de oferta. Furtado (1954) apresentou a necessidade de distinguir as abordagens que analisam a produção, menos genérica e abstrata, considerando especificidades históricas no curto prazo, daquelas que tratam da distribuição, mais abstratas, genéricas e dinâmicas ao longo da história. Em linhas gerais, para Furtado (1954), uma teoria econômica precisaria se prestar a analisar três aspectos: (i) o mecanismo da produção; (ii) a transformação histórica do processo de produção; e (iii) os elementos dinâmicos desse processo.

O nosso estruturalismo, surgido nos anos 50, empenhou-se em destacar a importância dos parâmetros não-econômicos dos modelos macroeconômicos. Como o comportamento das variáveis econômicas depende em grande medida desses parâmetros que se definem e evoluem num contexto histórico, não é possível isolar o estudo dos fenômenos econômicos de seu quadro histórico. (FURTADO, 2002, p. 72)

Contrariando o princípio da escassez ricardiano, a análise estrutural cepalina percebe que o crescimento econômico dos países subdesenvolvidos não é limitado pela oferta de mão de obra. Enquanto o crescimento econômico nos modelos clássicos advém do aumento da produtividade por trabalhador, tal fenômeno não poderia ser mensurado da mesma maneira nos países subdesenvolvidos, uma vez que o aumento do produto se dava pelo aumento da absorção de uma massa de trabalhadores informais e não pelo aumento da produtividade econômica. Nos países subdesenvolvidos, consequentemente, a taxa de crescimento da razão capital-trabalho $(\mathrm{K} / \mathrm{L})$ pode se manter constante para qualquer quantidade de capital em virtude da oferta de trabalho ilimitada que essas economias possuem. Nos países centrais, com economia industrial, os ajustes ao longo do ciclo econômico faziam-se pelas quantidades enquanto nos países periféricos, com economia primária, por meio dos preços. ${ }^{2}$

$$
\begin{gathered}
y=L_{p} P_{p} / L_{i} P_{i} \\
L_{p}<L_{i} \text { e } P_{p}<P_{i}
\end{gathered}
$$

2 Sobre a oferta ilimitada de mão de obra nos países subdesenvolvidos, uma contribuição que segue a mesma linha da CEPAL, porém realizada de forma mais apurada foi a de Arthur Lewis em seu artigo "A economia fechada" (1954). 
Em (1) e (2), $L$ refere-se à produtividade; $P$ corresponde a preço; $p$ e $i$ referem-se, respectivamente, a primário e industrializado.

As economias subdesenvolvidas da região foram estruturadas historicamente em um modelo de crescimento primário-exportador, hacia afuera. As economias periféricas cresceram com o impulso da expansão de setores de exportação de produtos primários para os centros industriais e não em um modelo hacia adentro, ou seja, mercado interno com desenvolvimento urbano-industrial (PREBISCH, 1949; FURTADO, 1954). Os condicionantes históricos e estruturais resultavam na deterioração dos termos de troca e a relação disfuncional e dicotômica entre centro e periferia. Esse cenário faz com as economias latino-americanas enfrentem os seguintes desafios para seu desenvolvimento: (i) superar a oferta ilimitada de mão de obra; (ii) combater a inflação estrutural; (iii) criar agentes de investimentos em razão da carência de poupança; e (iv) neutralizar o desequilíbrio na balança de pagamentos.

Para superar esse cenário Raúl Prebisch, Celso Furtado e outros pensadores cepalinos entenderam que o progresso nos países latino-americanos e o rompimento com o subdesenvolvimento deveriam ser pautados normativamente por uma política de industrialização baseada no modelo de substituição de importações (modelo ISI), no capital nacional para quebrar um padrão de centro-periferia e na integração regional mediante um regionalismo fechado. Nesse modelo, o Estado seria o principal agente econômico (BIELSCHOWSKY, 2000; HAFFNER, 2002).

Segundo os cepalinos percursores, a burguesia nacional latino-americana não era detentora de um capital forte capaz de industrializar a região, logo era incapaz de se tornar agente do investimento, fomentando o desenvolvimento por si só. O Estado deveria, portanto, alterar o padrão de políticas públicas, orientando-as para a composição de polos industriais e de investimentos na infraestrutura. As exportações de matérias-primas teriam de ser uma extensão do mercado interno, provendo ao mercado internacional somente seu excedente produtivo. É a retórica do Estado-empreendedor cepalino.

O Estruturalismo da CEPAL, na sua primeira fase, não foi uma teoria necessariamente planificadora, mas para superar a dicotomia centro-periferia professava que era fundamental a formação de uma capital nacional forte. Os altos comandos da economia (os serviços públicos, os recursos naturais, a indústria pesada e os transportes, bem como o controle sobre o comércio interno e externo) deveriam sempre ficar em mãos dos nacionais. Isso facilitaria ao Estado controlar o processo de tomadas de decisão, evitando choques e interferências externas.

Em linhas gerais, o desafio da CEPAL era aumentar a densidade de capital por homem empregado nos países periféricos por meio do investimento da industrialização e do avanço dos setores de maior coeficiente tecnológico. Esse desafio requeria 
bases sociopolíticas e uma teoria própria para não recair em adaptações microeconômicas e simplificações autárquicas. Uma leitura inovadora era necessária para aprofundar a análise e discriminar os diferentes impactos da condução das políticas econômicas no processo de acumulação de capital e sua relação com o mercado na América Latina. A perspectiva histórico-estrutural foi essencial para a construção da "sociologia concreta" no pensamento Cepalino enquanto o enfoque hipotético-dedutivo configurou a base da "sociologia analítica" (RODRIGUEZ, 2009).

$\mathrm{O}$ método histórico-estruturalista tornou-se referencial na comunidade acadêmica, convertendo-se no paradigma dominante na região. A retórica do Estado-empreendedor foi ao encontro das aspirações de importantes lideranças políticas e sociais da América Latina. A industrialização capitaneada pelo Estado deveria realizar a substituição de importações, a defesa da indústria nacional infante e o enfoque no mercado interno. O descolamento do centro dinâmico faria com que as questões estruturais da América Latina fossem sanadas, como o estrangulamento externo e a demanda interna insatisfeita com os bens de consumo. O modelo ISI foi amplamente empregado em diversas nações latino-americanas, com destaque para México, Brasil e Argentina. Esse, segundo Tavares (1977, p. 35), é: “[...] um processo de desenvolvimento parcial e fechado que, respondendo às restrições de comércio exterior, procurou repetir aceleradamente, em condições históricas distintas, a experiência de industrialização dos países desenvolvidos".

Na década de 1980, em consequência da crise da dívida externa e dos processos de hiperinflação vivenciados por diversos países da região, a CEPAL viu-se obrigada a mudar suas prioridades. Embora o modelo apregoado pelos Cepalinos tenha alcançado relativo sucesso, sobretudo nos maiores países da região citados, ao fornecer infraestrutura, poupança e capacitação para indústria nacional, o processo de industrialização per se foi insuficiente para proporcionar o desenvolvimento econômico dos países periféricos. A retórica desenvolvimentista baseada no modelo ISI e no papel empreendedor do Estado, dessa forma, foi aos poucos cedendo espaço para uma retórica de controle dos preços macroeconômicos, renegociação da dívida, busca pela estabilidade e por um desenvolvimento gerenciado, mas não capitaneado pelo Estado.

As principais obras da CEPAL, nos anos de 1980, foram: "La industrialización trunca de América Latina" (1983) e "Industrialización en América Latina: e la caja negra al casillero vacío" (1990), ambas do economista chileno Fernando Fajnzylber. O avanço dos preceitos da ortodoxia convencional via Consenso de Washington para os países da América Latina desde 1989 reforçaram a necessidade da CEPAL de realizar sua autocrítica. Os estudos de Fajnzylber são as bases para essa reavaliação, viabilizando, assim, o avanço teórico-científico no método histórico-estruturalista e a superação de alguns enunciados na retórica da Comissão. 
O economista chileno era crítico ao neoliberalismo vigente na região, mas também apontavam os equívocos do modelo Estado-empreendedor adotado anteriormente. Ao mesmo tempo em que precisava incorporar temas centrais do modelo ortodoxo convencional (ajuste fiscal, abertura econômica, por exemplo), a CEPAL não poderia perder suas raízes analíticas (Estruturalismo-histórico) e seu escopo basilar (desenvolvimento econômico dos países latino-americanos). Desse modo, os pesquisadores Cepalinos, na década de 1990, estabeleceram uma nova síntese de ideias que atualizou a retórica do método histórico-estruturalista, mas não modificou o próprio método em si. Surgiram, nesta época, o método histórico-neoestruturalista e a retórica do Estado-gerencial.

O documento "Transformación productiva com equidade" (CEPAL, 1990) inaugurou as premissas básicas do Neoestruturalismo e da nova retórica. O documento faz um resumo das experiências dos países latino-americanos na década de 1980 e denuncia os problemas do balanço de pagamentos deficitário e a desorganização das contas públicas. O caminho era modernizar o Estado, fazendo com que ele deixasse de ser Estado-empreendedor e passasse a ser Estado-gerencial. Seria um Estado mais pontual, capaz de reverter os desequilíbrios fiscais, fazer uma melhor inserção no sistema do comércio mundial, possibilitando, dessa maneira, a transformação produtiva com equidade dos países da região.

Os principais nomes dessa segunda fase cepalina, além de Fernando Fajnzylber, são Gert Rosenthal, Osvaldo Sunkel, José Antonio Ocampo, José Luis Machinea, Joseph Ramos e Ricardo Ffrench-Davis. A TPE, apregoada pelos neoestruturalistas, tem como meta modernizar as dinâmicas político-econômicas internas sincronicamente em que relativiza a dicotomia entre o centro e a periferia. $\mathrm{O}$ caminho é agregar valor aos produtos e aumentar o padrão tecnológico da indústria. A abertura econômica de bens e serviços e a poupança externa teriam papel determinante nessa meta. A preocupação com o controle dos altos comandos da economia pelo capital nacional não aparece no Neoestruturalismo. $\mathrm{O}$ ajuste fiscal sem pressão sobre o nível dos salários é peça fundamental para a estabilidade e o crescimento, proporcionando a denominada TPE (CEPAL, 1990, 1998).

Para o Neoestruturalismo, o progresso técnico deve ser percebido não só como endógeno às atividades produtivas e às empresas, mas também como condicionado por forças endógenas peculiares de cada economia, sociedade e país ou região (RODRIGUEZ, 2009). A interação entre as empresas com os diversos atores e seus modos de interação forma o chamado "sistema nacional de inovação", que pode resultar mais ou menos favorável à geração e à incorporação de progresso técnico e no aumento dos níveis de competitividade internacional de cada economia.

Fajnzylber (1990) evidencia o progresso técnico como elemento-chave do desenvolvimento, mas simultaneamente aponta a atividade industrial como âmbito essen- 
cial do desenvolvimento tecnológico. Em meio ao um novo paradigma tecno-econômico, a tecnologia é mais complexa e o progresso técnico mais intenso e acelerado; no entanto, nas ondas de atividades e de mercados tecnologicamente avançados surgem as "janelas de oportunidade” disponíveis para as economias atrasadas.

A continuidade do crescimento e da industrialização nas economias periféricas estava sujeita a uma tríplice dinâmica constituída pelo progresso técnico, pela acumulação de capital e pelo crescimento do produto. Ademais, o Neoestruturalismo propõe um crescimento decididamente extrovertido, enfatizando as recomendações ao fomento da livre concorrência e da diminuição da importância da intervenção estatal, admitindo a conveniência de se acentuar a desregulação dos mercados em diversos âmbitos. O capital externo ganha destaque em um modelo de desenvolvimento-associado.

Verifica-se que o Neoestruturalismo mantém a lógica do Estado como ator fundamental, porém a retórica muda, o Estado não é empreendedor, mas o gerenciador dos conflitos. O Neoestruturalismo atualiza o modelo anterior entendendo que a industrialização per se não é suficiente, ou seja, industrializar é condição necessária, mas não suficiente, para o desenvolvimento. A industrialização é importante, mas é essencial priorizar o tipo de industrialização que tem sua base na produção de bens intensivos em tecnologia para superar a condição de subdesenvolvimento. Para tanto é fundamental um novo modelo baseado na competitividade, na inserção externa e no regionalismo aberto e centrado na produção intensiva em tecnologia. A busca da TPE desloca o modelo ISI para o hall de experiência histórica da CEPAL.

A TPE foi propagada constantemente em importantes documentos da Comissão. A nova percepção era de que haveria a necessidade da reestruturação dos setores industriais com resultados pouco eficientes em matéria de capacidade produtiva e inovadora, denunciando os grandes déficits externos e a persistência de vulnerabilidade externa por ação da instabilidade nas contas correntes de capital.

En particular, la sociedad suele confiar al Estado un papel muy crucial en la promoción de la equidad, y el pacto fiscal resulta incompleto e insatisfactorio si ese papel se omite, se descuida o se cumple insuficientemente. Aquí resultan de importancia tareas de promoción de la igualdad de oportunidades, con sus expresiones, por ejemplo, en el ámbito de la educación, la salud y el empleo, y tareas de protección a poblaciones vulnerables; y no puede quedar descuidada la equidad con que se recauden los recursos que el Fisco emplea para éstas y para sus demás tareas. (CEPAL, 1998, p. 11)

Segundo Missio, Jayme Jr. e Oreiro (2013), o Neoestruturalismo adaptou a CEPAL para a realidade das novas circunstâncias históricas. De acordo com Gwynne e Kay (2004), essa adaptação no método histórico-estruturalista se fez incorporando tanto os 
conhecimentos, as ferramentas e os modelos da ortodoxia convencional quanto os avanços teóricos e conceituais das teorias das escolas Neoschumpeteriana, pós-Keynesiana e institucionalista. Em um contexto de estabilidade macroeconômica, abertura comercial e desregulamentação financeira, o Neoestruturalismo enfocou a competitividade sistêmica promovida pela concorrência intercapitalista e gerenciada pelo Estado.

De acordo com Bielschowsky (2009), se Fajnzylber foi o responsável pela inauguração do Neoestruturalismo, Ocampo foi quem mais o consolidou e o aperfeiçoou. Para Ocampo (2005), o crescimento econômico nos países em desenvolvimento está intrinsecamente ligado à dinâmica das estruturas de produção e às políticas e instituições específicas criadas para apoiá-la, especialmente aquelas que facilitam a difusão de inovações geradas no mundo industrializado e a criação de vínculos entre empresas e setores nacionais. Nesse interim, evitar a instabilidade macroeconômica é essencial, contudo não suficiente. A estabilidade precisa ser compreendida em um sentido amplo, incluindo além da inflação e dos desequilíbrios fiscais insustentáveis, os ciclos econômicos acentuados, os preços relativos voláteis, os desequilíbrios insustentáveis em conta corrente e os balanços arriscados do setor privado.

Segundo Ocampo (2005), uma característica regular do crescimento econômico é o movimento simultâneo de uma série de variáveis econômicas: tecnologia, acumulação de capital humano, investimento, poupança e mudanças sistemáticas nas estruturas de produção e de consumo. Taxas de investimento mais elevadas, consideradas essenciais para a aceleração do crescimento econômico, são em grande parte o resultado dos mecanismos aceleradores gerados pelo crescimento dinâmico. A acumulação de capital humano é também um fator essencial no crescimento econômico, mas a acumulação de habilidades é em grande parte resultado da experiência produtiva e da expansão dos sistemas educacionais, gastos com setores relacionados ao sucesso do crescimento econômico.

As assimetrias entre centro e periferia, conforme apresentado por Prebisch (1949) e Furtado (1961), são em parte determinadas pelo próprio desenvolvimento histórico da economia internacional. A hierarquia econômica mundial está associada à alta concentração na geração de tecnologia, à concentração igualmente alta de finanças mundiais e à dependência de empresas multinacionais. Por essas razões, o desenvolvimento econômico não é uma questão de passar por estágios dentro de um padrão uniforme associado ao aumento da renda per capita que os países industrializados já seguiram.

O desenvolvimento econômico, para os neoestruturalistas, trata de aumentar a renda per capita, de ter sucesso nas transformações estruturais endógenas e de empregar as estratégias macroeconômicas e financeiras adequadas. Essas, por sua vez, são resultado da interação entre duas forças básicas, embora multidimensionais: (i) as inovações (novas atividades, processos de aprendizagem e a difusão por meio do sistema econô- 
mico); e (ii) as complementaridades, ligações ou redes entre empresas e atividades de produção, e as instituições necessárias às complementaridades (OCAMPO, 2005).

O Neoestruturalismo entende, ademais, que a condição de subdesenvolvimento não se explica predominantemente por distorções exógenas induzidas pela política econômica, mas também por fatores econômicos e sociopolíticos históricos e estruturais endógenos. De acordo com Missio e Jayme Jr. (2011), são exemplos de fatores econômicos endógenos do subdesenvolvimento: (a) a distribuição desigual da renda e da riqueza; (b) a concentração da propriedade; (c) a inserção desfavorável do comércio mundial; (d) a elevada concentração dos mercados; e (e) o atraso tecnológico. Ao passo que os fatores sociopolíticos endógenos do subdesenvolvimento são: (a) a frágil organização sindical; (b) a desigualdade na distribuição geográfica e setorial da população; e (c) o baixo nível educacional. A TPE seria, dessa maneira, promovida pelas junções de fatores e de ações tanto endógenos quanto exógenos.

Com a TPE, o Neoestruturalismo elege a busca pela equidade social como um dos fatores determinantes para o desenvolvimento. Enquanto a ortodoxia convencional, propalada pelo Consenso de Washington, acredita que o principal agente econômico capaz de promover uma maior equidade seja as próprias forças do livre-mercado, para o Neoestruturalismo, o Estado continua sendo agente determinante para o fim das desigualdades. Os programas sociais podem até ser terceirizados para sociedade civil organizada, mas o Estado tem de criar marcos regulatórios para garantir que as pessoas em situação de necessidade sejam alcançadas (CEPAL, 1998).

La transformación productiva no podría ser simplemente la resultante de crear un clima macroeconómico apropiado y estable, o de aplicar una poUtica de "precios correctos". Exigirá combinar el manejo macroeconómico con políticas sectoriales, así como integrar las políticas de corto y de largo plazo. Además, precisará de cambios institucionales con orientaciones estratégicas también de largo plazo, en las que pueda asentarse una forma nueva de interacción entre los agentes públicos y privados, como vía ineludible de alcanzar la equidad y la armonía social. (CEPAL, 1990, p. 14-15)

Evidencia-se que o Neoestruturalismo atualizou o modelo anterior, particularmente ao entender que a industrialização não é suficiente, ou seja, industrializar é condição basilar, mas não autônoma para o desenvolvimento. Assim sendo, o tipo de industrialização, regulada por um Estado-gerencial, não mais empreendedor, que prioriza a produção de bens intensivos em tecnologia, é fundamental para superar a condição de subdesenvolvimento mediante a TPE. Para tanto é necessário um novo modelo baseado na competitividade, na inserção externa e no regionalismo aberto e centrado na produção intensiva em tecnologia. As instituições impactam tanto o comércio imperfeito quanto 
os aparatos públicos dominantes. A política econômica de curto prazo tem importância e a questão da igualdade social também ganha relevância.

\section{A ASCENSÃO DA MUDANÇA ESTRUTURAL PRODUTIVA PARA IGUALDADE (MEPI) NO NEOESTRUTURALISMO}

Em 2008, a CEPAL lançou o documento: "La transformación productiva 20 años después. Viejos problemas, nuevas oportunidades" (CEPAL, 2008). O cenário da economia mundial era de severa crise. Na América Latina, os países estavam vivendo o boom das commodities e algumas economias tinham conseguido estruturar verdadeiros polos de alta tecnologia com uso de capital humano qualificado, todavia sem êxito em democratizar esses ganhos para grande massa da população que continuava a viver marginalizada. O documento de 2008 faz um balanço da TPE e abre espaço para uma nova autocrítica cepalina.

De 2010 em diante, portanto, os documentos da CEPAL redirecionaram seu enfoque, deixando os preceitos da TPE em segundo plano. Os novos textos da Comissão dão maior destaque para questões político-sociais, clarejando temas como a desigualdade e a cultura do privilégio na América Latina. Conquanto, a denúncia dos neoestruturalistas Cepalinos contra a desigualdade e a cultura do privilégio nas sociedades latino-americanas já se encontrava nos textos acerca da TPE, foi somente com a subida da bióloga e ex-Secretária-Geral Adjunta de Gestão nas Nações Unidas Alicia Bárcena que esses temas tornaram o cerne dos documentos das seções centrais.

Os neoestruturalistas atuais consideram, sobretudo após a crise de 2008, que a equidade se obtém por meio da ação política e social do Estado, das organizações não governamentais (ONG) e da sociedade civil organizada. $O$ fim das desigualdades, para a CEPAL atualmente, não é consequência do desenvolvimento, mas pressuposto para almejá-lo (CEPAL, 2018). Os principais nomes da CEPAL que estão estruturando essa nova fase do Neoestruturalismo, além da própria Bárcena, são: Wilson Peres, Gabriel Porcile, Esteban Pérez, Pablo Yanes, Antonio Prado, Verónica Amarante e Martín Abeles, entre outros.

O primeiro documento a integrar o que denominamos da fase em prol da MEPI da CEPAL é "A hora da igualdade: brechas por fechar, caminhos por abrir" (2010). Esse afirma que sociedades menos desiguais tendem a possuir um sistema democrático mais estável, além de serem capazes de realizar planejamento de longo prazo oportunizando, assim, o desenvolvimento econômico e social. O documento começa respondendo o porquê desse novo enfoque no pensamento neoestruturalista Cepalino. 
Em primeiro lugar porque maior igualdade em matéria de direitos, oportunidades e bem-estar promove maior sentido de pertencimento à sociedade e, com isso, maior coesão social [...]. Em segundo lugar, uma sociedade mais integrada é condição para uma sociedade mais produtiva e com maior convergência produtiva. [...] Em terceiro lugar, maior igualdade no âmbito dos direitos sociais permite maior igualdade em termos de voz e visibilidade políticas. Dito de outro modo, uma maior integração ao trabalho digno, à educação de qualidade, à informação e ao conhecimento e às redes de proteção e interação sociais permite melhorar a capacidade dos cidadãos para participação em instituições políticas e sindicais, no diálogo público, no voto informado, no uso do conhecimento para fazer valer seus direitos no acesso a associações civis e no intercâmbio cultural. [...] Em quarto lugar, a experiência de crises anteriores na América Latina e no Caribe mostra que seu impacto na pobreza, no bem-estar e na inclusão social geralmente é mais profundo e duradouro que aquele encontrado na dinâmica da economia. (CEPAL, 2010, p. 40-41)

O texto afronta a desigualdade estrutural como algo que inviabiliza o desenvolvimento econômico e que é responsável por que haja baixa cooperação e coesão, logo baixa dinâmica econômica. O documento destaca veementemente a importância de promover pactos fiscais que auxiliem no financiamento de políticas públicas. A criação de fundos de coesão social é publicitada como forma de repasse ou subsídios cruzados com propósito de transferir recursos ou prover serviços aos que não podem pagar por eles. Os pactos fiscais e os fundos de coesão social são ferramentas capazes de conter os efeitos da volatilidade externa da América Latina e com capacidade de consolidar instituições, proporcionando maior coesão e cooperação social para o desenvolvimento (CEPAL, 2010).

Outro ponto relevante desse relatório de 2010 é a diferenciação entre capital humano e capacidade humana. Segundo CEPAL (2010), o conceito de "capital humano" centra demasiadamente em um mero ajuste meritocrático baseado no "valor" dos indivíduos no mercado. É a valorização das potencialidades humanas reduzidas meramente a uma relação de oferta e de demanda de trabalho. O relatório prefere optar pelo conceito de capacidade humana. Esse é caracterizado pela igualdade de direitos como acesso à educação e ao conhecimento, mas juntamente é preciso que o Estado exerça seu papel redistributivo e regulador em três níveis: (i) na dimensão territorial; (ii) no emprego; (iii) na proteção social. O objetivo é colocar a igualdade na contribuição produtiva e também no desenvolvimento social. É a valorização do indivíduo como cidadão e não somente do trabalhador e do consumidor. A cidadania com suas titularidades de direitos, portanto, deve ser o eixo da inclusão econômica, social e política nas economias da América Latina. 
Em 2012, o relatório "Mudança estrutural para a igualdade: uma visão integrada do desenvolvimento" (2012) não só continua com o mesmo enfoque, mas também o aprofunda e o apura. O documento deixa claro seu afastamento dos preceitos da TPE ao operacionalizar e diferenciar os conceitos de "equidade" e "igualdade". Segundo texto:

Diferentemente da noção de equidade, a de igualdade implica não apenas corrigir as lacunas em termos de oportunidades, mas também contar com um claro compromisso do Estado para redistribuir os frutos do desenvolvimento, buscar um maior equilíbrio na distribuição dos fatores de produção e no aproveitamento dos ganhos de produtividade por esses fatores, definir um marco normativo explícito de direitos sociais que leve ao estabelecimento de pactos fiscais em torno da prestação de serviços universais e estar mais aberto a pensar não apenas em pisos e mínimos, mas também em tetos e máximos. (CEPAL, 2012, p. 14)

A TPE cede espaço para a proposta de Mudança Estrutural Produtiva para Igualdade (MEPI). A CEPAL, na fase da MEPI, admite que a transformação produtiva não conseguirá obter efeitos multiplicadores na sociedade e na política se ficar restrita à criação de ilhas de alta tecnologia e de produtividade em meio a um mar de setores de subsistência e primários. Trata-se de algo que foi evidenciado em alguns países da América Latina, isto é, vários tecnopolos rodeados de áreas urbanas e rurais degradantes. Desse modo, a MEPI modifica a leitura da TPE e dedica mais destaque para a questão da igualdade e do meio ambiente.

A MEPI é caracterizada por dois tipos de eficiência capazes de combinar trajetórias de crescimento da produtividade, da produção e do emprego ao logo do tempo. São elas: "eficiência schumpeteriana"3 e "eficiência keynesiana" (CEPAL, 2012, p. 18). Além disso, as políticas sociais e redistributivas são peças chaves na MEPI. Elas “[...] evitam a concentração e propagam, de maneira mais solidária, os ganhos ao longo de toda a sociedade" (CEPAL, 2012, p. 20). A MEPI apresenta uma visão integrada de desenvolvimento. Os aspectos sociais, ambientais, políticos e identitários se juntam aos econômicos. A MEPI é uma visão de longo prazo para profundas transformações

3 Na "eficiência schumpeteriana" setores com as taxas mais altas de crescimento da produtividade, com maior difusão de conhecimentos e capacidades para o conjunto da economia e da sociedade, lideram o processo de inovação, impulsionando os aumentos de produtividade, tanto no seu próprio setor quanto para outros setores (spillover effect).

4 Na "eficiência keynesiana" ou "de crescimento" a economia tem um padrão de especialização em setores beneficiados por taxas mais altas de crescimento da demanda externa e interna, com efeitos positivos sobre a produção e o emprego. 
sociais. A política ganha maior destaque nessa fase da CEPAL, enfatizando a importância das instituições democráticas e do investimento em capacidade humana em detrimento do capital humano.

No texto "Pactos para a igualdade: rumo a um futuro sustentável” (2014), a CEPAL explicita que os documentos das seções centrais sofreram uma modificação desde 2010, formando uma nova concepção de pensar. O lema dessa nova fase, segundo a própria CEPAL, é: “igualar para crescer e crescer para igualar" (CEPAL, 2014, p. 5). O texto de 2014 retoma o conceito de mudança estrutural e o sintetiza da seguinte forma:

A perspectiva da mudança estrutural exige um manejo do ciclo econômico que se traduza na maior ocupação possível da capacidade instalada durante seu transcurso. Ao mesmo tempo é necessário promover, por meio de políticas industriais, a inovação e o investimento para incorporar em forma crescente o conhecimento e construir capacidades endógenas no âmbito tecnológico e produtivo, criando vantagens comparativas dinâmicas. Este processo não significa deixar de aproveitar os ciclos de alta de preços dos recursos naturais, mas ter claro que isto não é suficiente para construir bases sólidas e sustentáveis de crescimento [...]. Por outro lado, a proteção e o investimento social, devem estar conectados de forma a promover, de forma combinada, a igualdade e o dinamismo produtivo. $\mathrm{O}$ investimento na primeira infância, a proteção frente a choques externos mediante transferências básicas de renda, a criação de sistemas de cuidado que contribuam a este investimento e à plena incorporação da mulher ao mercado de trabalho são elementos constitutivos da própria transformação estrutural, dado que: incrementam capacidades humanas, igualam oportunidades e resultados, trazem coesão à sociedade e atacam as causas fundamentais da reprodução intergeracional da exclusão. (CEPAL, 2014, p. 7)

O relatório destaca a sustentabilidade e a preocupação com as gerações futuras. Para CEPAL (2014), a dinâmica virtuosa depende de melhores instituições e estruturas propícias para o desenvolvimento sustentável e para igualdade social. É preciso, dessa maneira, criar ambiente capaz de elaborar novos pactos sociais com objetivo de construir marcos regulatórios de médio e de longo prazo em distintas esferas. Dentre os pactos a CEPAL enumera os seguintes:

[...] um pacto pelo investimento e a mudança estrutural; um pacto fiscal por um melhor equilíbrio entre bens privados e serviços públicos na arquitetura do bemestar; um pacto de governança dos recursos naturais e preservação do meio ambiente, com ênfase na solidariedade com as gerações futuras e uma matriz 
produtiva mais diversificada e verde, e um pacto social e trabalhista, para potencializar a capacidade de redistribuição do Estado em distintos âmbitos da desigualdade e para que a institucionalidade laboral acompanhe a mudança estrutural a fim de reduzir brechas de gênero, de produtividade, de emprego de qualidade e de apropriação entre capital e trabalho. (CEPAL, 2014, p. 12)

O documento da seção de 2014 descreve, ainda, ações para cada pacto que ele elenca. A ênfase, no entanto, é no conceito e nas ações da sustentabilidade, apresentando, inclusive, um capítulo sobre padrões de consumo e desenvolvimento. Tal fato demonstra que a CEPAL realçou a preocupação de estar em consonância com os discursos e o referencial teórico de outras comissões da ONU. Essa preocupação fica mais evidente no documento da seção central de 2016 que recebe o título de: "Horizontes 2030: a igualdade no centro do desenvolvimento sustentável”.

O relatório de 2016 inicia-se descrevendo que está havendo uma mudança de época na história da humanidade. O crescimento econômico está cedendo espaço para a preocupação do desenvolvimento sustentável. Os modelos de organização produtiva, o capitalismo e o socialismo marxista promoveram degradação ambiental sistemática pelo esgotamento de recursos naturais não renováveis e pela poluição generalizada de elementos vitais. $\mathrm{O}$ antigo modelo de desenvolvimento econômico não se atenta para a sustentabilidade, pois confunde eficiência com máxima extração e transformação dos recursos.

A humanidade está em um processo de mudança de paradigma socioeconômico e político, incorporando e ressignificando modos de produção e de sociabilidade. O documento da CEPAL de 2016 salienta essa transformação e ressalta o papel da ONU com a "Transformando Nosso Mundo: a Agenda 2030 para o Desenvolvimento Sustentável” e os “Os 17 Objetivos de Desenvolvimento Sustentável (ODS) ” - que os 193 países representados na Assembleia Geral das Nações Unidas aprovaram em setembro de 2015 - como sendo os projetos mais amplos e ambiciosos com desejo de promoverem um caminho para essa mudança (PNUD, 2015).

O objetivo central do texto aprovado no período de sessões da CEPAL em 2016 é de ser complementar aos demais documentos da ONU, isto é, a “Agenda 2030" e os "Objetivos de Desenvolvimento Sustentável", contudo analiticamente tem base na perspectiva estruturalista do desenvolvimento e sob o ponto de vista dos países da América Latina e Caribe (CEPAL, 2016). Para visão neoestruturalista cepalina, o conceito ordenador tem de ser o da mudança estrutural progressiva.

O conceito ordenador é a mudança estrutural progressiva, definida como um processo de transformação para atividades e processos produtivos que apresentem três características: ser intensivos em aprendizagem e inovação (eficiência schumpeteriana), estar associados a mercados em rápida expansão, que permitam 
aumentar a produção e o emprego (eficiência keynesiana) e favorecer a proteção do meio ambiente e o desacoplamento entre crescimento econômico e emissões de carbono (eficiência ambiental). Para obter estruturas produtivas com estes três tipos de eficiência, que tornem compatíveis a igualdade e a proteção ambiental, é preciso um novo conjunto de instituições e coalizões políticas que as promovam em nível global, regional, nacional e local. (CEPAL, 2016, p. 10)

Os países da América Latina e Caribe enfrentam dois desafios concomitantemente: busca de acumulação de capital para conseguirem se desenvolver e preocupação com a proteção ambiental. Para CEPAL (2016), a MEPI é a forma encarregada de fazer com que as nações da região abandonem sua trajetória do passado comprometida com o crescimento a qualquer custo, sem, entretanto, se assentar nos preceitos da ortodoxia convencional. Esses antigos modelos representam uma acumulação insustentável e associada a um conflito distributivo de crescente intensidade, gerando fragmentação social, institucional e política.

De acordo com CEPAL (2016), a América Latina tem de caminhar para um novo estilo de desenvolvimento, pautado na ação coletiva e nos pactos de longo prazo. Isso possibilitaria a estruturação de sociedades democráticas promotoras da igualdade, da transparência e da participação, além de ter o foco na produtividade, nos empregos de qualidade e no cuidado do meio ambiente, por meio da difusão das novas tecnologias num grande impulso ambiental. A questão é como seguir os preceitos Cepalinos e alcançar esses objetivos, efetivando assim, a MEPI? Os documentos de 2010, 2012, 2014 e 2016 fornecem alguns caminhos, contudo é no documento de 2018, intitulado "A ineficiência da desigualdade", que a síntese de ideias dessa nova fase do Neoestruturalismo elege claramente a indispensabilidade de superação da cultura do privilégio na América Latina e Caribe para a concretização da MEPI.

Segundo o estudo, a América Latina e o Caribe possuem uma cultura do privilégio que tem origens desde a conquista e a colonização da região pelos países centrais. Por mais de 500 anos, o conquistador, o colonizador, o crioulo, o fazendeiro, o aristocrata e o político adotaram uma cultura de negação do outro no continente latino-americano e caribenho. Ao controlar o Estado, essa elite menosprezou os povos originais, os afrodescendentes, os mestiços, os zambos, as mulheres e, quando as repúblicas foram estabelecidas, estendeu-se a negação aos imigrantes, aos camponeses, aos analfabetos, aos habitantes de favelas e aos trabalhadores (CEPAL, 2018).

Para CEPAL (2018), a cultura do privilégio pode ser entendida a partir de três traços: (i) a naturalização da diferença como desigualdade; (ii) a justificativa da diferença com base na posição, adscrição racial ou de gênero, origem, cultura e poderes políticos e econômicos; (iii) a perpetuação dos privilégios e da hierarquia por meio do 
aparelhamento de instituições que determinam regras e práticas, estabelecendo uma dialética entre a naturalização da diferença como desigualdade e a reprodução das desigualdades por meio de estruturas e de instituições sociais.

Nesta dialética, a cultura do privilégio garante assimetrias em múltiplos âmbitos da vida coletiva, como o acesso a posições privilegiadas nos negócios e nas finanças; o poder decisório ou deliberativo; a maior ou menor presença em meios que impõem ideias, ideologias e agendas políticas; a captura de recursos públicos para benefícios privados; condições especiais de justiça e sistema fiscal; contatos para ter acesso a melhores empregos e serviços; e facilidade para obter os melhores lugares para viver, circular, educar-se, abastecer-se e cuidar-se. (CEPAL, 2018, p. 49-50)

A cultura do privilégio, por conseguinte, inviabiliza com que o Estado corte recursos ou realize reformas em setores econômicos, sociais e políticos que mantêm essa hierarquia. Os privilegiados se apoderam do Estado e suas instituições, colocando-os a seu serviço. O impedimento de reformas estruturais faz com que, para melhorar a situação da população marginalizada bem como para impulsionar a MEPI, os governos progressistas optem por adotar o populismo econômico e não por concretizar as reformas estruturais. Por isso na América Latina e no Caribe o populismo tanto político quanto econômico é tão recorrente.

O populismo econômico, para Sachs (1990), pode ser caracterizado por políticas monetárias expansionistas que desequilibram o balanço de pagamentos, o déficit público e pressiona a inflação. Para Dornbusch e Edwards (1991), o populismo econômico nasce da necessidade do governante de atentar às contradições existentes dentro do arranjo de forças sociais que dão alicerce ao seu governo. O mandatário - comprometido com pautas progressistas e desenvolvimentistas na América Latina - ao receber apoio tanto de setores das elites e de grupos do funcionalismo público pertencentes ao círculo de privilegiados, quanto de populares, teria, inevitavelmente, dificuldades para efetivação de políticas públicas que atendessem à demanda da nação ao mesmo tempo em que se mantêm os privilégios, o aparelhamento e a naturalização da desigualdade. Tal estrutura social-política-econômica leva o governo progressista e desenvolvimentista a adotar medidas econômicas pouco sustentáveis em longo prazo, gerando um crescimento no estilo stop and go.

Para provocar a MEPI, o recente estudo da CEPAL de 2018 elenca como exemplo de reforma estrutural essencial a tributária. Segundo CEPAL (2018), o sistema tributário da América Latina e Caribe preserva a cultura do privilégio. As isenções, a elisão e o baixo imposto sobre a renda nos países da região geraram uma carga tributária indireta e regressiva, recaindo sobre o consumo e atingindo mais fortemente a classe mé- 
dia e pobre. A carga tributária média dos países latino-americanos é a metade da média de um conjunto de 15 países da União Europeia (UE). Na região, a taxa efetiva de carga tributária sobre a renda do decil X alcançou 4,8\% em 2014, em contraste com uma média de 21,3\% nos 15 membros da UE avaliados (OCDE, 2016).

A carga tributária no Brasil, por exemplo, está, atualmente, em 33,63\% do Produto Interno Bruto (PIB). A carga tributária brasileira é alta. O nível de impostos cobrados no país é similar ao de nações desenvolvidas: Alemanha, 37\%; Espanha, 33,6\%; Reino Unido, 32,5\%; e Suíça, 27,9\%. Conquanto a classe média e pobre sofra mais com a cobrança via consumo do que a elite, o país tem baixa tributação sobre renda e patrimônio. No Brasil, a arrecadação com impostos sobre patrimônio está na faixa de 3\%, enquanto a média mundial é de $10 \%$. A participação dos impostos sobre renda na arrecadação no país está em 20,9\%. Ao passo que a média dos 35 países que fazem parte da Organização para a Cooperação e o Desenvolvimento Econômica (OCDE), que reúne os países desenvolvidos e alguns em desenvolvimento, é de 34,3\% (OCDE, 2016).

O documento de 2018 encerra responsabilizando a cultura do privilégio e o atual estilo de acumulação de capital como os principais perpetuadores da distância entre as nações do centro e da periferia. A concentração de renda nos países latino-americanos estabelece castas de privilegiados, facultando o aparelhamento do Estado e suas instituições por essas castas e naturalizando a desigualdade. A banalização da desigualdade e do aprovisionar do Estado faz com que medidas em favor da MEPI sejam atravancadas, emperrando o catching-up e o desenvolvimento de fato da região. Para CEPAL, nessa fase da MEPI, os países da região somente romperão a condição atual que se encontram se implementarem um novo desenvolvimento mais inclusivo e sustentável.

\section{CONSIDERAÇÕES FINAIS}

O nascimento institucional da CEPAL em 1948 também marcou a origem de uma nova corrente teórico-metodológica: o Estruturalismo-histórico latino-americano. A partir da identificação de características estruturais historicamente determinadas, o pensamento Cepalino propõe explicar as peculiaridades do funcionamento das economias periféricas, mormente as da América Latina, e o que as mantêm subdesenvolvidas. Para a Comissão, a única forma de compreender as particularidades e as singularidades dos países subdesenvolvimentos da região é adotando uma posição não reducionista por meio do Estruturalismo. O método da CEPAL é capaz de reconhecer a complexidade das mudanças estruturais, da trajetória e da densidade histórica de cada nação diferentemente do método da escola clássica, que ainda confia na capacidade do mercado equacionar os desequilíbrios da América Latina. 
Talvez por ser fruto de uma instituição multinacional preocupada com a melhoria do padrão de vida nos países latino-americanos, o campo teórico-metodológico do Estruturalismo-histórico sempre esteve preocupado não somente em interpretar a realidade, mas em transformá-la. Por essa razão a CEPAL, em todas suas etapas, construiu uma retórica forte em defesa de formulações de políticas econômicas capazes de romper com o subdesenvolvimento da região. Nessa perspectiva, este estudo categorizou o pensamento Cepalino em duas fases distintas: a primeira é a do Estado-empreendedor e do método histórico-estruturalista (1948-1990) e a segunda, a do Estado-gerencial e do método histórico-neoestruturalista (1990-atualidade).

Na primeira fase, entre 1948 e 1990, o diagnóstico apresentado pelos intelectuais Cepalinos, como a condição de subdesenvolvimento, a deterioração nos termos de troca e a heterogeneidade estrutural, levou a uma série de propostas de políticas econômicas que seriam responsáveis pela promoção da industrialização por substituição de importações, caracterizando assim a atuação do Estado-empreendedor. A economia, nessa fase, contemplava a atuação estatal em várias esferas, seja via políticas macroeconômicas (fiscal, monetária e cambial), seja na atuação direta no setor produtivo de insumos industriais básicos, seja na captação de poupança externa e financiamento do empresário nacional.

Todavia, o sucesso parcial do modelo ISI, a crise econômica da década de 1980 e a retomada do liberalismo como paradigma hegemônico, representado pelo Consenso de Washington em 1989 na América Latina, refletiram diretamente na evolução teórica e no posicionamento Cepalino pós-1990. Em meio a crises de dívida, hiperinflação e baixo crescimento nos países latino-americanos, a CEPAL se renovou por meio da incorporação de ferramentas e de modelos da ortodoxia convencional, bem como dos avanços teóricos e conceituais das teorias Neoschumpeteriana, pós-Keynesiana e institucionalista, fazendo surgir, assim, o método histórico-neoestruturalista.

No alvorecer dos anos 1990, o documento "Transformación productiva com equidade" inaugurou as premissas básicas do Neoestruturalismo e dessa nova fase. $\mathrm{O}$ Neoestruturalismo manteve sua base no método histórico-estrutural e na lógica hipotético-dedutivo estabelecidos pelos precursores do pensamento Cepalino. A análise, entretanto, avançou nos aspectos endógenos para o desenvolvimento ao apresentar as hipóteses interrelacionadas sobre comportamentos dos agentes econômicos (empresários, consumidores, grupos sociais, políticos) a fim de demonstrar como que esses arranjos sociais, políticos e econômicos preservam o subdesenvolvimento na região. Assim, o Neoestruturalismo entendia que a condição de subdesenvolvimento não se explicava predominantemente por distorções exógenas induzidas pela política econômica, mas também por fatores econômicos e sociopolíticos históricos e estruturais endógenos. 
Se o método passou por avanços, incorporando novos estudos do pensamento econômico, a retórica da CEPAL modificou drasticamente com o Neoestruturalismo. A retórica desenvolvimentista baseada no modelo de substituição de importações e no papel empreendedor do Estado foi aos poucos cedendo espaço para uma retórica de controle dos preços macroeconômicos, renegociação da dívida, pela busca pela estabilidade e por um desenvolvimento gerenciado, mas não capitaneado pelo Estado. Nessa direção, o Estado mantém-se como ator fundamental, porém como gerenciador dos conflitos. É o fim do Estado-empreendedor e a defesa do Estado-gerencial. O Estado continua sendo agente determinante para o fim das desigualdades. Contudo, faz-se necessário um novo modelo baseado na competitividade, na inserção externa e no regionalismo aberto e centrado na produção intensiva em tecnologia para alcançar a equidade.

No Neoestruturalismo e na TPE, a luta histórica em prol da industrialização, da homogeneidade produtiva e da melhoria da concentração de renda concedem lugar a uma maior preocupação com o padrão e as capacidades tecnológicas, a eficiência e a integração produtiva e também a estabilidade macroeconômica. Os preceitos da TPE trouxeram, ademais, o foco para os temas da redistribuição de renda e da equidade. Ambas temáticas já estavam presentes, embora com menor ênfase, desde a década de 1950 .

Após a crise econômica mundial de 2008, os documentos centrais da CEPAL redirecionaram seu enfoque, deixando os preceitos da TPE em segundo plano e dando maior destaque para questões político-sociais sobre o tema da desigualdade e do privilégio na América Latina. Não é uma mudança de método, mas de retórica. O marco dessa mudança é o relatório de 2010, intitulado: "A hora da igualdade: brechas por fechar, caminhos por abrir”. A partir desse documento, começa a nascer uma nova retórica cepalina embasada na MEPI.

Desde 2010, os preceitos da TPE concederam espaço para as propostas da MEPI que foram apresentadas nos cinco documentos das seções centrais subsequentes e em textos complementares. A superação da TPE pela MEPI ocorre em consequência de diversos fatores, tais como a crise econômica, os novos estudos no campo da economia institucional, schumpeteriana e neokeynesiana, mas, sobretudo, em razão de a transformação produtiva não ter conseguido obter efeitos multiplicadores na sociedade e na política, ficando restrita à criação de ilhas de alta tecnologia e produtividade. Era preciso rever a retórica. Portanto, o conceito de "equidade" é substituído pelo de "igualdade". O de "capital humano" é descartado e é operacionalizado o conceito de "capacidade humana”, além de se introduzir a expressão de "cultura do privilégio" para definir uma estrutura historicamente estabelecida e que determina e particulariza as relações sociais, políticas e econômicas na América Latina. 
Nesse conjunto de novas ideias e de leitura da realidade, a MEPI intenta enfocar a questão da igualdade e do meio ambiente, além de incorporar uma visão de longo prazo para profundas mudanças estruturais. $\mathrm{O}$ fator político ganha maior destaque nessa fase da CEPAL, enfatizando a importância das instituições democráticas. A CEPAL, ademais, está tentando se articular com outros projetos da ONU, tais como a “Agenda 2030" e os “Objetivos de Desenvolvimento Sustentável”.

Infere-se que o giro pelos principais estudos concebidos pela CEPAL ao longo de sua existência permite evidenciar, que diferentemente de outras comissões da ONU, a CEPAL não é somente um órgão burocrático multilateral, mas é uma escola de pensamento econômico. A construção de um pensamento econômico ímpar pela Comissão se deve muito à criação do método histórico-estruturalista pelos percursores e mantido até a atualidade. A retórica pode se modificar (ISI, TPE e, atualmente, MEPI); no entanto, o método se mantém e até mesmo avança. Este trabalho procurou destacar essas progressões e alterações no pensamento Cepalino, dando maior destaque para o advento de uma nova concepção: a MEPI. Acredita-se que a hipótese elencada pela pesquisa foi validada e o objetivo alcançado.

\section{REFERÊNCIAS}

BIELSCHOWSKY, R. "Cinquenta anos do Pensamento na CEPAL - Uma resenha". In: BIELSCHOWSKY, R. (Org.). Cinquenta anos do Pensamento na CEPAL. Vol. 1. Rio de Janeiro: Record, 2000.

BIELSCHOWSKY, R. Sesenta años de la CEPAL: estruturalismo y neoestruturalismo. Revista de la CEPAL, n. 97, p. 173-194, 2009.

CEPAL - COMISSÃO ECONÔMICA PARA A AMÉRICA LATINA E CARIBE. Estudo econômico da América Latina. Santiago de Chile: CEPAL, 1949.

CEPAL - COMISSÃO ECONÔMICA PARA A AMÉRICA LATINA E CARIBE. Report of the ad hoc Committee on the proposal for an economic commission for Latin America. Santiago de Chile: CEPAL, 1988.

CEPAL - COMISSÃO ECONÔMICA PARA A AMÉRICA LATINA E CARIBE. Transformacion Productiva con Equidad: La tarea prioritaria del desarrollo de América Latina y el Caribe em los años noventa. Santiago de Chile: CEPAL, 1990.

CEPAL - COMISSÃO ECONÔMICA PARA A AMÉRICA LATINA E CARIBE. Antecedentes sobre la creación de la CEPAL: fotocopias de documentos de la Asamblea General y del Consejo Económico y Social de las Naciones Unidas. Santiago de Chile: CEPAL, 1998.

CEPAL - COMISSÃO ECONÔMICA PARA A AMÉRICA LATINA E CARIBE. La transformación productiva 20 años después. Viejos problemas, nuevas oportunidades. Santiago de Chile: CEPAL, 2008. 
CEPAL - COMISSÃO ECONÔMICA PARA A AMÉRICA LATINA E CARIBE. A hora da igualdade: brechas por fechar, caminhos por abrir. Santiago de Chile: CEPAL, 2010.

CEPAL - COMISSÃO ECONÔMICA PARA A AMÉRICA LATINA E CARIBE. Mudança estrutural para a igualdade: uma visão integrada do desenvolvimento. Santiago de Chile: CEPAL, 2012.

CEPAL - COMISSÃO ECONÔMICA PARA A AMÉRICA LATINA E CARIBE. Pactos para la igualdad: hacia un futuro sostenible. Santiago de Chile: CEPAL, 2014.

CEPAL - COMISSÃO ECONÔMICA PARA A AMÉRICA LATINA E CARIBE. Horizontes 2030: a igualdade no centro do desenvolvimento sustentável. Santiago de Chile: CEPAL, 2016.

CEPAL - COMISSÃO ECONÔMICA PARA A AMÉRICA LATINA E CARIBE. A ineficiência da desigualdade. Santiago do Chile: CEPAL, 2018.

DORNBUSCH, R.; EDWARDS, S. The macroeconomics of populism in Latin America. Chicago: The University of Chicago Press, 1991.

FAJNZYLBER, F. La industrialización trunca de América Latina. México, DF: Editorial Nueva Imagen, S.A, 1983.

FAJNZYLBER, F. Industrialización en América Latina: de la 'caja negra' al 'casillero vacío. Cuadernos de la CEPAL, n. 60, 1990.

FURTADO, C. La teoria del desarrollo en la evolución de la teoria económica. El Trimeste Económico, julio-septiembre, p. 241-264, 1954.

FURTADO, C. Desenvolvimento e Subdesenvolvimento. Rio de Janeiro: Fundo de Cultura, 1961.

FURTADO, C. Em busca de novo modelo: reflexões sobre a crise contemporânea. Rio de Janeiro: Paz e Terra, 2002.

GWYNNE, R. N.; KAY, C. Latin America transformed: globalization and modernity. Londres: Hodder Education, 2004.

HAFFNER, J; A. A CEPAL e a industrialização brasileira (1950-1961). Porto Alegre: EDIPUCRS, 2002.

LEWIS, A. W. Economic development with unlimited supply of labor. The Manchester School, v. 22, n. 2, p. 139-191, 1954.

MISSIO, F.; JAYME Jr., F. Structural heterogeneity, and endogeneity of elasticites on the balanceof-payments constrained growth model. Texto para Discussão, UFMG/CEDEPLAR, 2011.

MISSIO, F. J.; JAYME Jr., F. G.; OREIRO, J. L. Resgatando a tradição estruturalista na economia. In: ENCONTRO NACIONAL DE ECONOMIA, 41, Foz do Iguaçú, Paraná, 9-13 dez. 2013.

OCAMPO, J. Beyond reforms: structural dynamics and macroeconomic vulnerability. Palo Alto: Stanford University Press, 2005.

OCDE - ORGANIZAÇÃO PARA A COOPERAÇÃO E DESENVOLVIMENTO ECONÔMICO. Taxing wages in Latin America and the Caribbean. Paris: OCDE, 2016.

PREBISCH, R. El desarrollo económico de la América Latina y algunos de sus principales problemas. Boletín Económico de América Latina, Santiago de Chile, v. 7, n. 1, 1962[1949]. 
PNUD - PROGRAMA DAS NAÇÕES UNIDAS PARA O DESENVOLVIMENTO. Transformando nosso mundo: a Agenda 2030 para o Desenvolvimento Sustentável. Nova Iorque: ONU, 2015.

PNUD - PROGRAMA DAS NAÇÕES UNIDAS PARA O DESENVOLVIMENTO. Os 17 objetivos do desenvolvimentismo sustentável. Nova Iorque: ONU, 2015.

PREBISCH, R. Dinâmica do desenvolvimento latino-americano. Rio de Janeiro: Fundo de Cultura, 1964.

RODRIGUEZ, O. O estruturalismo latino-americano. Rio de Janeiro: Civilização Brasileira, 2009.

SACHS, J. Conflito social e políticas populistas na américa latina. Revista de Economia Política, v. 10, n. 1, jan./março, p. 1-27, 1990.

TAVARES, M. C. Da substituição de importações ao capitalismo financeiro: ensaios sobre economia brasileira. Rio de Janeiro: Zahar Editores, 1977. 